\title{
Baseline survey: Summary report of district Jhelum
}

Pakistan Initiative for Mothers and Newborns (PAIMAN)

Follow this and additional works at: https://knowledgecommons.popcouncil.org/departments_sbsr-rh

Part of the Family, Life Course, and Society Commons, and the Maternal and Child Health Commons How does access to this work benefit you? Let us know!

\section{Recommended Citation}

Pakistan Initiative for Mothers and Newborns (PAIMAN). 2006. "Baseline survey: Summary report of district Jhelum." Islamabad: Population Council. 


\section{Baseline Survey Summary Report}

This summary report presents some of the key findings of a 2005 baseline household survey in Jhelum district, one of the ten districts in Pakistan that are the focus of the PAIMAN project. The Pakistan Initiative for Mothers and Newborns (PAIMAN) is a five-year project funded by the United States Agency for International Development (USAID). PAIMAN is committed to assist the Government of Pakistan in its implementation of the full spectrum of interventions necessary to address maternal and neonatal health $(\mathrm{MNH})$ issues. The PAIMAN district survey results are presented individually; the districts are: Rawalpindi, Jhelum, Khanewal and DG Khan in Punjab; Dadu and Sukkur in Sindh; Jaffarabad and Lasbela in Balochistan; and Upper Dir and Buner in North West Frontier Province.

PAIMAN has developed a monitoring and evaluation plan to ensure that the success of the project was properly ascertained, and that the appropriate lessons learned. PAIMAN conducted the baseline household survey in the ten districts in order to understand local $\mathrm{MNH}$ perceptions and practices. The study population included all currently married women of reproductive age (15-49 years) living in all urban and rural areas of the district. The sampling design was a stratified, systematic sample of households.

In Jhelum, 705 women were interviewed, of whom 524 (74 percent) were rural. Fifty-nine percent of respondents were literate. On average, respondents had borne 3.7 children, of whom 3.3 were still living. 


\section{Knowledge,}

\section{Attitude}

\section{and Behavior}

Figure 1: Percentage of married women in Jhelum who know at least 3 danger signs

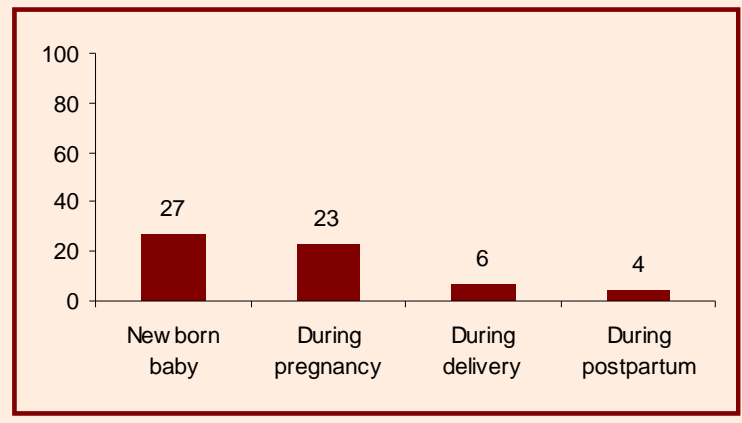

Figure 2: Percentage of married women in Jhelum who received antenatal care, TT injections and iron folate during their last pregnancy

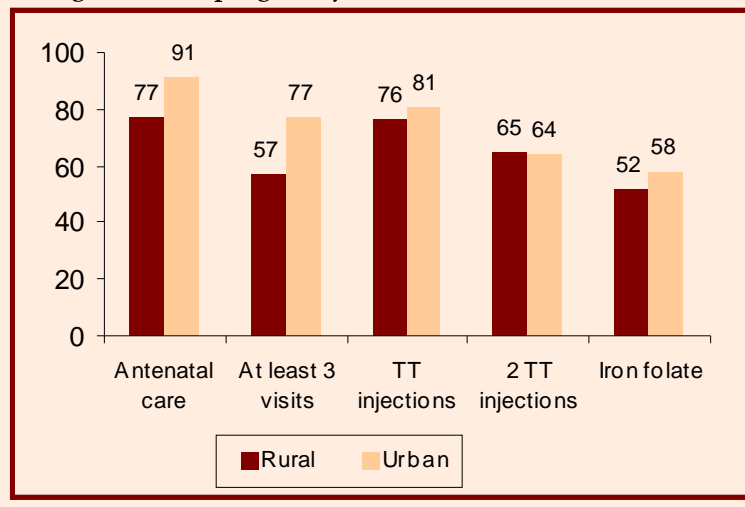

Figure 3: Percentage of married women in Jhelum who receive antenatal counseling during their antenatal visits, by topic counseling

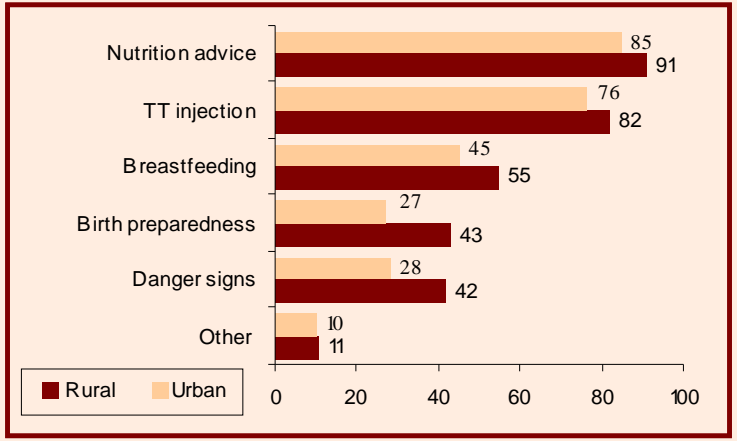

\section{Few Women Know Danger Signs Well}

\section{Knowledge of danger signs}

Only a small proportion of married women recognize three or more danger signs during pregnancy, during delivery, in the postpartum period, and in newborns (figure 1).

\section{Source of information regarding danger signs}

* Most receive information from their in-laws, family members and friends.

* About 26 percent indicate that they receive information primarily from television.

* Only 26 percent in rural areas indicate that Lady Health Workers are their source.

* District/Tehsil Headquarter Hospitals are also a source for about 17 percent in rural areas and 12 percent in urban areas.

\section{Most Women Receive Antenatal Care}

* Over 95 percent consider it necessary for women to receive antenatal checkups

* Most believe that an antenatal check-up should occur in the first three months of pregnancy.

* For their last pregnancy, 77 percent of rural and 91 percent of urban women had at least one antenatal check-up but only 57 percent of rural and 77 percent of urban women had 3 or more, the national standard.

* Nearly 80 percent in urban areas and 75 percent in rural areas had TT injections during their last pregnancy, while 60 percent in rural and 64 percent in urban areas had 2 or more TT injections.

* Over half took iron folate tablets during their last pregnancy.

\section{Components of antenatal check-up}

Figure 3 suggests that most women are not advised about preparing for emergencies, although most receive advice about nutrition and injections for tetanus.

\section{Many Women Prepare for Childbirth and Deliver in Facilities}

\section{Preparedness for childbirth}

Figure 4 shows that a large percent of women appear to have made appropriate arrangements for delivery, including majorities who prepare for possible emergency by arranging for money and transport.

\section{Place of delivery and services}

* A majority (95 percent) agree that delivery services should be obtained from skilled birth attendants.

* Data obtained on the births that occurred during the last three years, show that 50 percent of rural and 34 percent of urban women deliver their babies at home.

* Sixty percent of deliveries were conducted by a skilled birth attendant. 


\section{Delivery characteristics}

From figure 6, almost 71 percent of rural and 59 percent of urban respondents indicate they had a normal vaginal delivery. The proportion of Caesarean sections in urban Jhelum is rather high.

\section{Complications During Pregnancy and Childbirth are Common}

Nearly 57 percent of urban and rural pregnant women indicate they experienced a complication during their last pregnancy. Severe lower abdominal pain, severe headache, and high blood pressure are the complications most reported.

About one-fourth from urban and 30 percent from rural Jhelum report experiencing at least one complication during delivery. About 17 percent in rural areas report experiencing excruciatingly abnormal pain during their last delivery, whereas only 9 percent in urban areas report the same. Premature ruptures of membranes, excessive bleeding and prolonged labor were among other reported complications. For many of these complications, women receive no care or inappropriate care.

\section{Postpartum and Newborn Care Need Attention}

\section{Postpartum check-up}

* In both rural and urban Jhelum, about half feel that postpartum care is not necessary. Married women are often not aware of the complications that can arise following birth, and may ignore the symptoms.

* For those who delivered their last baby at home, 82 percent did not receive any postnatal check-ups.

* Among those who go for postnatal care, one-tenth go within 24 hours after childbirth.

\section{Immediate care of newborn}

* While almost one-fifth of the mothers (18 percent) report that their newborns were with them immediately following delivery, a large percent indicate that their newborns are placed on either a piece of cloth (rural: 51 percent) or on a mattress (urban: 56 percent).

* About 11 percent of mothers indicate that their newborns are placed on the floor immediately after delivery.

* About 69 percent the newborns are given a bath within one hour of birth; 15 percent are given one after the recommended six hours.

\section{Colostrum and breastfeeding}

Over 92 percent of urban and rural mothers indicate that they did breastfeed their child. In rural areas, 83 percent state that they gave colostrum to their babies; 79 percent do so in urban areas. Of those who gave colostrum to their newborns, 16 percent gave it within the first hour after birth. More than half, in both rural and urban areas, report giving the baby something other than breast milk within the first 3 days.

\section{Neonatal care}

* Forty-two percent of newborns were examined by a skilled provider at birth.

* Immediately after birth, mothers were most likely to note weak/no cry and difficult breathing. Jaundice is the most commonly noted complication in newborns within the first seven days.

* Most common choices (48 percent for in urban and rural Jhelum) for children's treatment are private hospitals and clinics.

* No external treatment was sought for reported symptoms in 18 percent of rural cases and 27 percent of urban.

\section{Clean Delivery Practices}

Respondents who delivered their last child at home report the following delivery practices:

* TBA did not wash her hands with soap for 12 percent of rural and 4 percent of urban deliveries.

* TBAs did not use a new blade for cutting the cord for at least 24 percent of rural deliveries and 42 percent of urban deliveries. Scissors and knives were reportedly used by TBAs.

* A new piece of thread was used for tying the cord for 78 percent of the deliveries.

Figure 4: Percentage of married women in Jhelum who made delivery arrangements, by type of arrangement

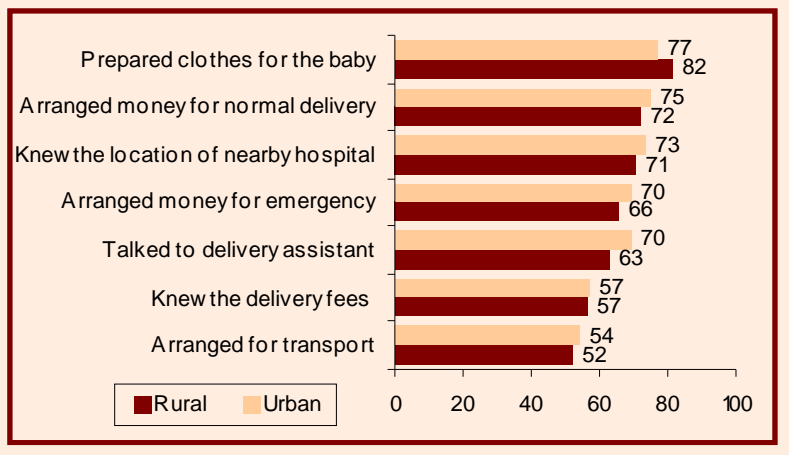

Figure 5: Percentage of married women in Jhelum who gave birth in the preceding three years, by place of delivery

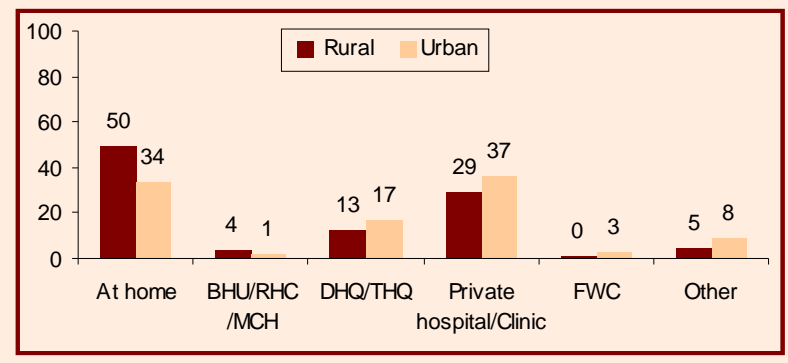

Figure 6: Percentage of married women in Jhelum who gave birth, by type of last delivery

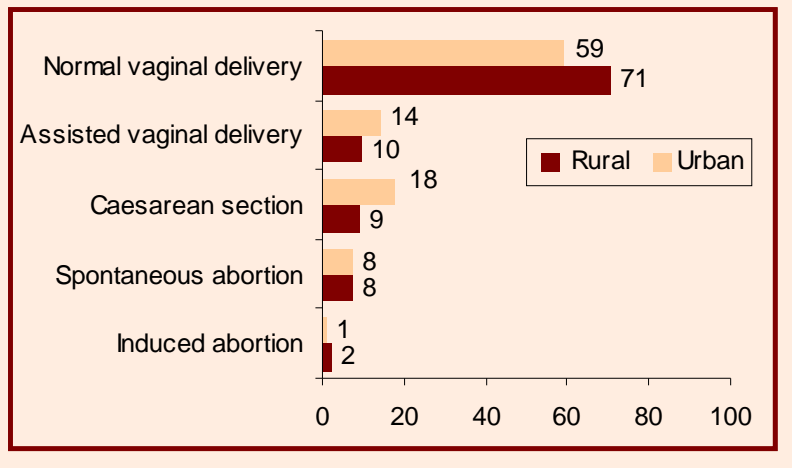




\section{Three Delays}

Delays in deciding to seek care, in reaching adequate health facilities, and in receiving appropriate care at health facilities lead to most maternal deaths.

\section{First delay: decisions must be made quickly}

* Women are prepared for delivery (figure 4) but don't know danger signs well (figure 1), so are not well placed to make emergency decisions.

* Women report themselves (21 percent) or their husbands (38 percent) most likely to make decisions for emergency delivery.

\section{Second delay: transport must be at hand and available}

* Of those seeking treatment for complications, 56 percent used own transport or private transport to reach the health facility.

* The average waiting time for transport was 15 minutes.

- Transport averages 20 minutes to reach the desired facility, but in 12 percent of deliveries, it takes more than one hour.

\section{Third delay: emergency services must be ready}

* After reaching the health facility, 94 percent report receiving services within 30 minutes. The median waiting time is 5 minutes.

* Appropriateness and quality of those services could not be ascertained.

\section{Access to media}

About three-fifths in rural areas watch television, compared to 79 percent in urban areas (figure 7). Few women listen to radios or read newspapers. About 74 percent in Jhelum has access to some sort of media, whether it is television, radio or newspapers.

Figure 7: Percentage of married women in Jhelum who have access to mass media, by type of media

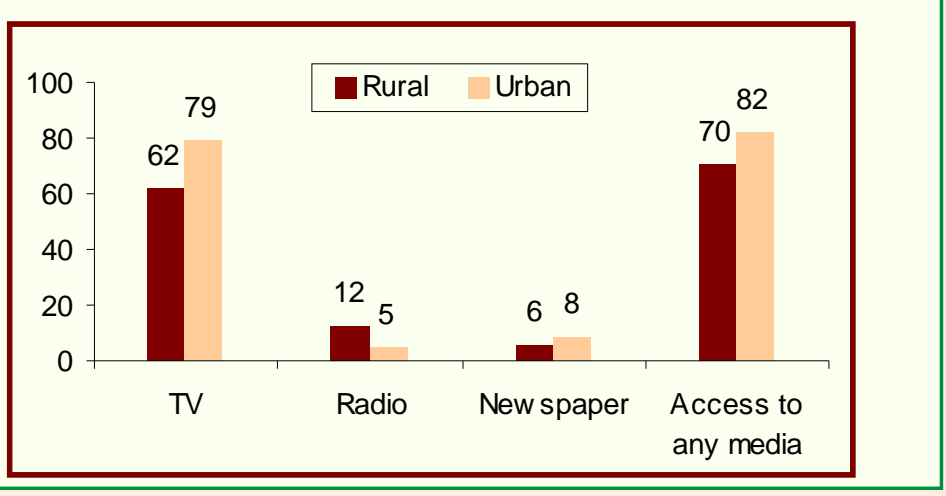

\section{Many pregnancies are unwanted}

- Forty-two percent of respondents were using family planning at the time of the study. About half of these (22 percent) were using withdrawal or condom, which have high failure rates. Thirty-four percent said they intended to use family planning in the future.

- Forty-nine percent of mothers said that their last child was either unwanted or mistimed. If unwanted pregnancies could be prevented in the first place, the attendant morbidity and mortality could be avoided.

\footnotetext{
JSI Research \& Training Institute, Inc.
CA \# 391-A-00-05-01037-00 project is funded by the United States Agency for International Development and implemented by JSI Research \& Training Institute, inc. in conjunction with Aga Khan University, Contech International,

Greenstar Social Marketing, Johns Hopkins University/CCP, PAVHNA, The Population Council, and Save the Children USA.
} 